severiana a la Baixa Antiguitat", en $C Y P$ SELA, VIII. (1990), 193-218.

RE:moLA., J. A., y ABFlLó, A., 1989: «Les àmfores", en Un abocador del segle $r d$. C. en el Fórum Provincial de Tàrraco, Memòries d'excavacio 2, Tarragona 1989, 249-320.

TED'A, 1989 a: Un abocador del segle i d. $C$. en el Fòrum Provincial de Tàrraco, Memòries d'excavació 2, Tarragona, 1989.
TED'A, 1989 b: «El foro provincial de Tarraco, un complejo arquitectónico de época flavia", en Archivo Español de Arqueología,62 (1989), 141-191.

Whitehouse, D.; Barker, G.; Refle, R., y Refse, D.. 1982: "The Schola Praeconum I: The coins, Pottery, Lamps and Fauna», en $P a$ pers of the British School at Rome, L (1982), 53-101.

\title{
ÁNFORAS ITÁLICAS DE ÉPOCA TARDORROMANA EN HISPANIA. LOS HALLAZGOS DEL PALMAR HOTEL (PREMIÀ DE MAR, BARCELONA)
}

\author{
POR
}

\author{
RAMÓN COLL i MONTEAGUDO \\ Museu Municipal d’Estampació Tèxtil. \\ Premià de Mar (Barcelona).
}

$\mathrm{Y}$

RAMÓN JÁRREGA DOMÍNGUEZ

Escuela Española de Historia y Arqueologia, C.S.I.C. Roma.

\section{RESUMEN}

En este trabajo estudiamos un nuevo tipo de ánfora recientemente identificado, perteneciente a la época tardorromana. Estas ánforas probablemente transportaban vino, que era usado para abastecer la ciudad de Roma y eventualmente se comercializaba en otros paises del Imperio; al menos, éste es el caso de Hispania, evidensiado por los materiales que aqui estudiamos.

\section{SUMMARY}

In this work, we study a recently known kind of Italian amphora of Late Roman times. These amphorae probably carried wine, used to supply the city of Rome and eventually for trade with other countries of the Empire; at least, this is the case of Hispania, evidenced by the materials studied here.
El estado actual de conocimientos sobre las ánforas tardorromanas ${ }^{1}$ pone de manifiesto la preponderancia casi absoluta de los productos africanos (en los que se envasaba principalmente vino y salazones) entre finales del siglo $\| \mathrm{y}$ el siglo vı d. C., así como la presencia (menor pero no insignificante) de producciones anfóricas procedentes del Mediterráneo oriental. La citada preponderancia de los productos norteafricanos envasados en ánforas coincide plenamente con el auge comercial de la zona correspondiente a la actual Túnez, que además de por los

\footnotetext{
I Una extensa clasificación tipológica y un pormenorizado estudio de conjunto sobre las ánforas tardorromanas puede verse en Keay 1984 passim.
} 
elementos citados se confirma por la exportación de vajilla de mesa (sigillata africana $C$ y D) y lucernas ${ }^{2}$, asi como, a otros niveles más lujosos, la comercialización de sarcófagos ${ }^{3}$ y la existencia de talleres musivarios de origen o inspiración africana que se encuentran ampliamente documentados en el Mediterráneo occidental.

En contraste con esta situación, el potencial exportador de los productos itálicos se encontraba en retroceso desde el siglo id. C., pudiendo considerarse la península itálica durante la Antigüedad Tardia más como un área importadora que exportadora. Prácticamente la única excepción a esta tónica (aunque significativa) que puede señalarse es la comercialización de sarcófagos de taller romano, que tiene una florecimiento muy importante en época constantiniana, $y$ otro periodo significativo a finales del siglo iv e inicios del v d. C. ${ }^{4}$.

Con respecto a la comercialización de ánforas itálicas durante el Medio y el Bajo Imperio en Hispania contamos solamente con un posible ejemplar de Tarragona (Keay 1984, vol. I, pág. 372 , fig. 171 , núm. 8 ) que ha sido identificado por Manacorda (1987, pág. 44) como un ánfora de Empoli, que se produjo en el área de dicha ciudad etrusca en los siglos III y iv d. C.

Sin embargo, debemos tener en cuenta que existe una forma anfórica, la Keay LII, fechada en los siglos iv y $\vee$ d. C. (Keay 1984, vol. I, págs. 27-268) que se ha considerado sin seguridad (basándose en las características de la arcilla) como procedente del Mediterráneo oriental; recientemente, Arthur $(1989$, passim $)$ ha sugerido que estas ánforas podrian haberse fabricado en realidad en el Bruttium (Sur de Italia), donde al parecer se han localizado hornos en los que se producían ánforas de esta forma.

\footnotetext{
2 Confrontar Hayes 1972 y 1980 , asi como AAVV 1981, con tipologia y estudio completo de estos materiales.

${ }^{3}$ En relación a la exportación de sarcófagos africanos es ilustrativo el ejemplo de Tarragona, recientemente estudiado por Rodà (1990).

4 Sobre la importación de sarcófagos de taller romano en Hispania, véase Palol 1967 y Sotomayor 1975; una recopilación de los datos conocidos sobre la presencia de estos sarcófagos en la zona catalana (con bibliografia anterior) puede encontrarse en Járrega, en prensa.
}

De todos modos, $y$ aun aceptando que todas las ánforas de la forma Keay LII sean de origen itálico, su difusión no es en absoluto masiva, por lo que no puede compararse cuantitativamente con la de los productos africanos y orientales ${ }^{5}$.

En lo que respecta a Hispania, la presencia de ánforas itálicas tardoimperiales es solamente testimonial, aun considerando como tales las correspondientes a la forma Keay LII ${ }^{\circ}$; sin embargo, los hallazgos de los que seguidamente nos ocuparemos, si bien no cambian sustancialmente este panorama, si que permiten matizarlo de forma bastante significativa.

\section{IDENTIFICACIÓN DE UN NUEVO TIPO DE ÁNFORA}

Recientemente ha sido identificada por Clara Bencivenga una nueva forma de ánfora itálica que se ha documentado en las excavaciones de Gricignano (Caserta, Campania) en Italia (Bencivenga 1987 passim). Puede considerarse, desde un punto de vista estrictamente formal, «nueva» sólo hasta cierto punto, puesto que presenta estrechos paralelismos con la forma Dressel $2 / 4$, que se produjo en Italia (y más tarde en otras zonas) a finales de la época romana republicana e inicios del Imperio. Sin embargo, existe un hiatus de más de doscientos años entre el periodo final conocido de la producción de dichas ánforas y la cronología de los ejemplares hallados en Gricignano; por otro lado, y desde el punto de vista estrictamente formal, se diferencian estos últimos de la clásica forma Dressel $2 / 4$ por tener unos perfiles marcadamente cilindricos, más masivos, alargados y rectilineos (Bencivenga 1987, pág. 396), no siendo siempre las asas bífidas, característica esta última propia de las Dressel 2/4 itálicas.

\footnotetext{
5 Sobre la difusión de las ánforas de la forma Keay LII confrontar Keay 1984, vol. Il, págs. 653-654 y Arthur 1989. págs. 134 y 140-141 (apéndice III), éste último con un mapa de distribución (pág. 138, figura 3).

6 Se han hallado ánforas de la forma Keay LII en Ampurias (L'Escala, Gerona), Tarragona e Itálica (Santiponce, Sevilla); confrontar Keay 1984, vol. I, págs. 267-268 y vol. II, pág. 653; Arthur 1989, págs. 134, 138 (figura 3) y 141 (apéndice 111 ).
} 
El citado hiatus cronológico entre las Dressel $2 / 4$ típicas y las mencionadas ánforas bajoimperiales constituye $\sin$ duda un problema importante, que creemos que tenderá a resolverse a medida que se conozcan mejor las producciones itálicas de los siglos II y III d. C.? La estrecha similitud formal (pese a las diferencias antes señaladas) entre las ánforas de Gricignano y las Dressel $2 / 4$, así como la identidad de la zona de producción de ambas, nos hace pensar que lógicamente debe existir un nexo de unión entre las dos producciones, que aún no se conoce detalladamente.

Las ánforas localizadas en Gricignano fueron $\sin$ duda producidas en Italia, como lo demuestran las características físicas de la arcilla, que es compacta, de color rosado-rojizo, micácea, con pequeñas inclusiones de color negro y sin engobe (Bencivenga 1987, pág. 396). Su cronología puede establecerse con cierta aproximación, dado que fueron reutilizadas en enterramientos junto con ánforas de la forma Almagro 51 C-Keay XXIII, que al parecer proceden del Sur de Hispania y que se fechan entre los siglos III y $\mathrm{v} d$. C. (Keay 1984, vol. 1, pág. 178), además de ánforas de las formas Africana I y II (datadas entre finales del siglo $॥$ y mediados del v d. C.), Ostia IV, figura 169 y Beltrán 68 (Bencivenga 1987, pág. 396).

Un dato cronológico muy preciso para una datación post quem lo constituye la presencia de una copa de sigillata gris estampillada de producción gálica de la forma Rigoir $6 \mathrm{~B}$ reutilizada para cubrir la boca de una de las ánforas de la forma Almagro 51 C-Keay XXIII halladas en la necrópolis. Dado que estas cerámicas finas empiezan a producirse a partir del último cuarto del siglo iv podemos afirmar que la datación de la necrópolis de Gricignano puede situarse a finales del siglo Iv (Bencivenga 1987, pág. 397) o ya en el siglo v, posiblemente en su primera mitad.

\footnotetext{
' Algunas puntualizaciones importantes sobre las ánforas itálicas de este período pueden encontrarse en Arthur 1987, passim.
}

\section{LA DOCUMENTACIÓN DE ESTA PRODUCCIÓN EN HISPANIA: LOS HALLAZGOS DEL PALMAR HOTEL}

En el yacimiento del Palmar Hotel (Premià de Mar) se han hallado dos ejemplares (uno completo y otro fragmentario) que creemos poder atribuir a la misma producción anfórica detectada en Gricignano, y de los cuales nos ocuparemos seguidamente.

El enclave arqueológico de Palmar Hotel se encontraba en el término municipal de Premià de Mar, en la comarca catalana del Maresme, situada administrativamente en la actual provincia de Barcelona ${ }^{8}$. Pudo documentarse la existencia de una necrópolis de inhumación constituida por unas sesenta o setenta tumbas, que fue brutalmente destruida en el año 1976 por máquinas excavadoras, por lo que los trabajos arqueológicos (llevados a cabo por la Secció Arqueològica del Museu Municipal de Premià de Mar) tuvieron que hacerse en condiciones muy desfavorables; por esta razón, el conocimiento que tenemos sobre este yacimiento es muy parcial, aunque suficiente para hacerse una idea sobre el mismo. Asimismo, nada sabemos sobre el hábitat al que correspondía esta necrópolis.

Las tumbas de la necrópolis del Palmar Hotel correspondían a los típicos enterramientos de tégulas y de fosas (una de las cuales estaba cubierta por un suelo de opus spicatum), cuya datación es bastante problemática, puesto que se practicaron en un amplio marco cronológico que abarca todo el Alto y el Bajo Imperio romano, así como parte de la Alta Edad Media. El dato que más puede contribuir a precisar su cronologia ( $\mathrm{y}$ en estrecha relación con nuestro estudio) lo constituye el hallazgo de dos inhumaciones en ánfora, las únicas que se han constatado en esta necrópolis. La reutilización de ánforas (ya sea completas o fragmentadas) en

\footnotetext{
* Confrontar Llanas-Montalbán-Gómez 1977, passim; Prevosti 1981, págs. 120 a 127 y figura 42, núm. 9; Járrega en prensa. Sobre una excavación de parte de la necrópolis no afectada por la destrucción de 1976, véase CollCazorla, 1987, passim.

Queremos dejar constancia de nuestro agradecimiento a Ferran Bayés y Fernando Cazorla por su desinteresada colaboración en la eleboración del presente trabajo.
} 
los enterramientos es una técnica que empieza a utilizarse en el siglo III d. C.; por tanto, es a esta centuria o a un período posterior al que corresponden estas ánforas y al menos parte de la necrópolis.

Entre las tierras de este yacimiento se hallaron también (junto con otros materiales más antiguos) un fragmento de plato de la forma Hayes 50 de la sigillata africana $C$ (fechado entre el segundo cuarto del siglo III e inicios del Iv d. C.) y una moneda de Constantino I (Prevosti 1981, págs. 123 y 125) lo que de algún modo apunta también a que como mínimo en el siglo III (si no más tarde) la necrópolis estaba en plena actividad.

Seguidamente procederemos a describir las características de las dos ánforas anteriormente citadas. Ambas se conservan actualmente en el Museu Municipal de l'Estampació Tèxtil de Premià de Mar.

1. Ánfora completa (figs. 1 y 2 ). Se encontraba fragmentada aunque in situ, reutilizada en un enterramiento infantil. Debemos señalar que aunque presenta actualmente algunos defectos de restauración, el ánfora estaba deformada desde su fabricación, como se aprecia claramente en la visión frontal de una de las asas, que se muestra claramente deformada; como puede verse, ello no fue un obstáculo para su comercialización. La arcilla de esta ánfora es semidura, algo porosa, con desgrasante de cuarzo, caliza, mica plateada, arenas y algún fragmento (escaso) de olivina, con su característico tono brillante. La coloración de la arcilla es beige-anaranjada variando a rosado claro, presentando en algunos puntos una tonalidad anaranjada rojiza.

2. Cuello, borde y asas (fig. 3). Las asas tienen un perfil de tendencia eliptica, y son bifidas presentando dos acanaladuras, una interior y otra exterior. Arcilla dura, porosa y de aspecto hojaldrado, con abundante desgrasante de olivina, así como (en menor cantidad) de caliza, cuarzo y mica plateada. El color es rosado-anaranjado claro. Esta pieza presenta huellas de haber sido rota modernamente, lo cual sin duda se produjo durante la destrucción en 1976 de la necrópolis del Palmar Hotel.

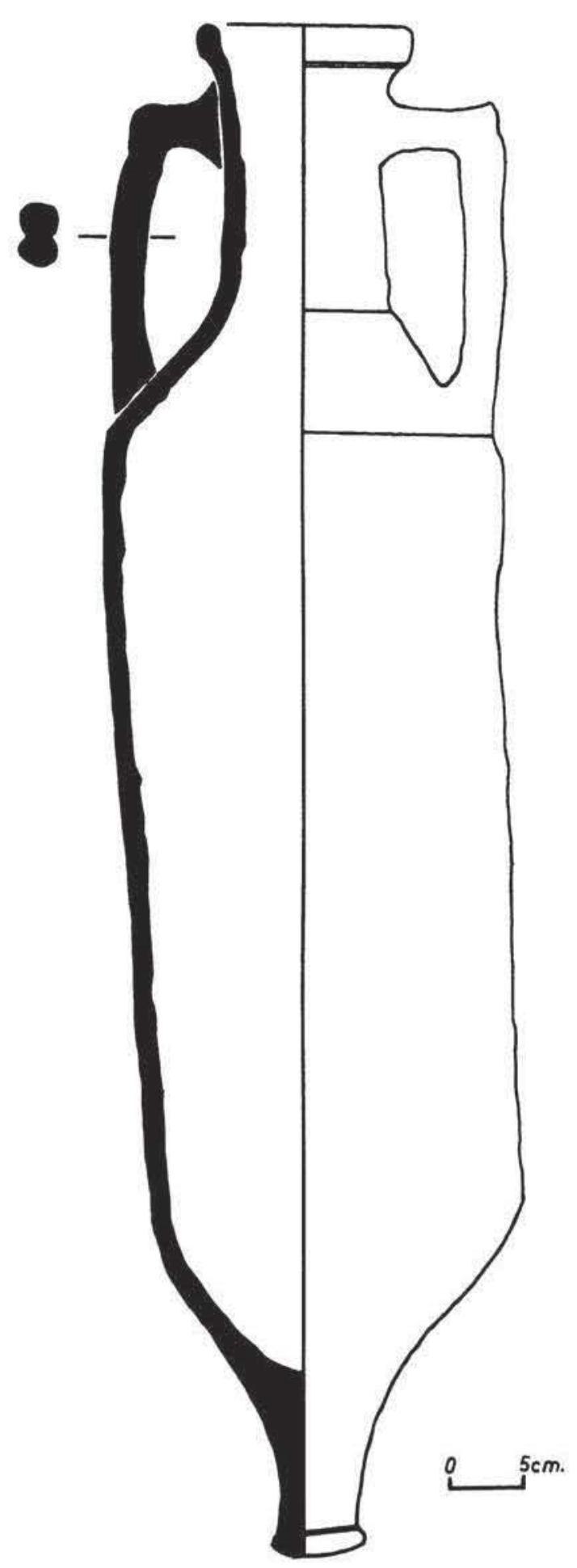

Figura 1.-Anfora número 1 del yacimiento del Palmar Hotel (Premià de Mar, Maresme, Barcelona). Escala 1:6. 


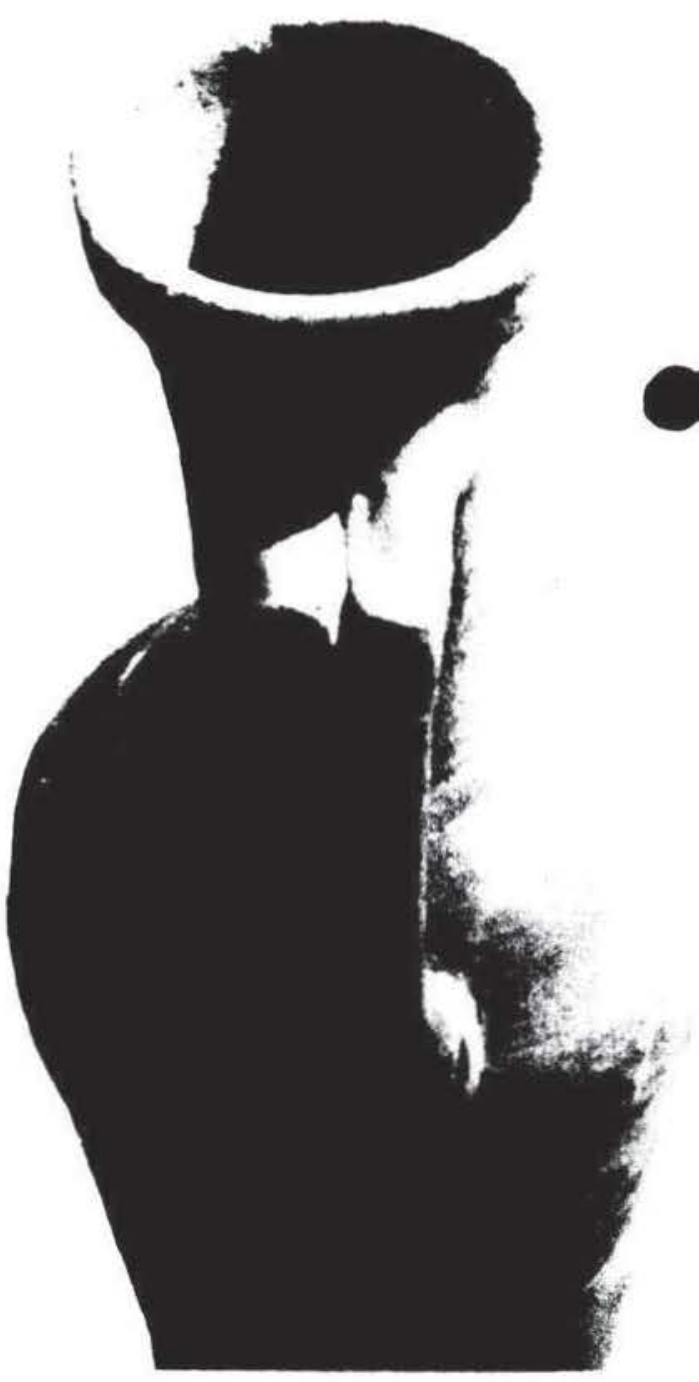

Figura 2.-Detalle superior del ánfora número 1, procedente del yacimiento del Palmar Hotel (Premià de Mar, Maresme, Barcelona). Foto: F. Cazorla.

Aunque estos dos ejemplares no habian sido estudiados a fondo y reproducidos gráficamente hasta ahora, el ánfora completa había sido ya razonablemente clasificada como perteneciente a la forma Dressel 2 por Prevosti (1981, pág. 125). Si bien el referente de esta forma resulta claro, creemos que con los datos actualmente conocidos es factible la asociación de estas ánforas con las localizadas en el yacimiento campano de Gricignano, por las siguientes razones:

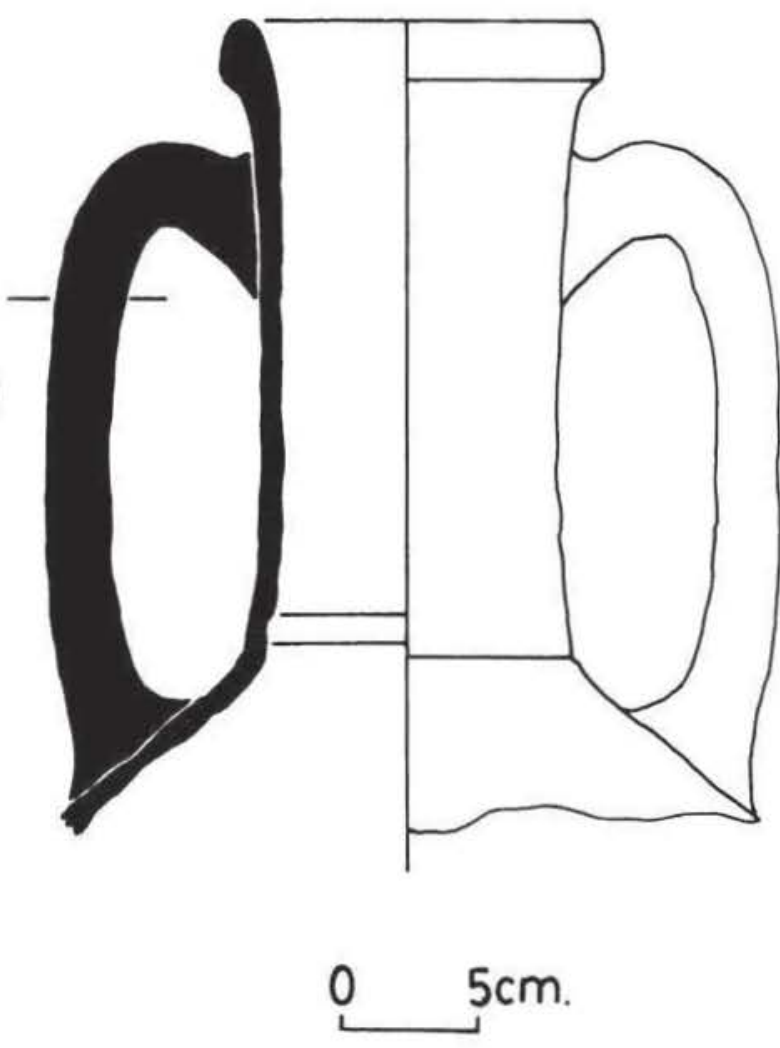

Figura 3.-Fragmento anfórico número 2 del yacimiento del Palmar Hotel (Premià de Mar, Maresme, Barcelona). Escala 1:9.

a) El análisis visual de la arcilla demuestra que se trata de productos itálicos.

b) Los perfiles (como se aprecia sobre todo en el ejemplar completo) alargados y fusiformes alejan estas ánforas del prototipo de la Dressel 2/4 acercándolos al mismo tiempo a las ánforas de Gricignano.

c) El hecho de que estas ánforas se encuentren reutilizadas en una necrópolis de inhumación permite atribuirles una cronología mínima del siglo III d. C., lo cual impide identificarlas como Dressel 2/4.

Es interesante poner de relieve que las características fisicas de los dos ejemplares que aqui estudiamos no son idénticas. Efectivamente, en el fragmento de cuello, borde y asas la concentración de desgrasante de olivina es muy grande, lo que junto con las características de 
la arcilla to hacen en todo semejante (en este aspecto concreto) a las ánforas vinarias romano-republicanas (Dressel 1 y Dressel 2/4) de procedencia itálica; en cambio, en el ejemplar completo este desgrasante, si bien es también evidente, aparece en mucha menor cantidad y mezclado con otro tipo de partículas. Es posible que ello se deba a la procedencia de ambos ejemplares de dos centros de producción diferentes, aunque éstos se encontraban sin duda en Italia.

Un problema bastante dificil de solventar es el de la cronología de estas ánforas. Dado que fueron reutilizadas para aprovecharlas como parte de unos enterramientos, es evidente que no pueden fecharse con anterioridad al siglo III, en el cual se inicia este tipo de reutilizaciones con tal finalidad; suponer que pueda tratarse de ejemplares más antiguos reaprovechados doscientos años después de su fabricación nos parece fuera de lugar, teniendo en cuenta que se trata de recipientes meramente utilitarios cuyo período de uso habia de ser muy reducido, por todo cuanto se conoce actualmente sobre las ánforas romanas.

La cronología mínima de estas ánforas, como hemos dicho, se sitúa en el siglo III d. C., pero es posible que en realidad sean más modernas. Considerando válida su relación con las ánforas localizadas en Gricignano, que se fechan a finales del siglo Iv o en la primera mitad del v d. C., podemos suponer para las del Palmar Hotel una fecha semejante. Sin embargo, el hecho de que estas ánforas correspondan a los dos únicos enterramientos de la necrópolis en los que se reutiliza este tipo de recipientes en una extensa zona de enterramientos de tégulas $y$ de fosa permite pensar que pueden corresponden a la fase inicial del uso de las ánforas en las necrópolis, lo que permitiria apuntar al siglo III d. C. Por otro lado, la presencia entre las tierras de la necrópolis de una moneda de Constantino I podria sugerir una datación más moderna, pero se trata de un dato demasiado aislado como para poder utilizarlo para este fin, puesto que su relación estratigráfica con los enterramientos no está clara.

En cualquier caso, los dos ejemplares de ánforas que hemos estudiado nos permiten afir- mar que se trata de productos itálicos (uno de los cuales defectuoso de origen, lo cual no le impidió ser comercializado) que tienen una cronología post quem del siglo III d. C., pudiendo muy bien corresponder al siglo iv o al $\mathrm{v}$ debido a su paralelismo con las ánforas de Gricignano.

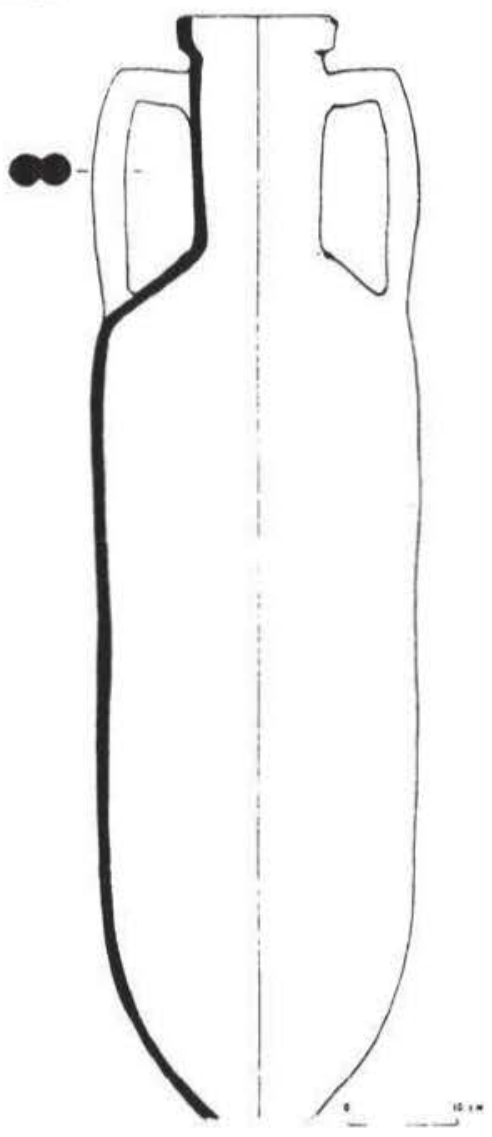

Figura 4.-Ȧnfora casi completa procedente del yacimiento de Gricignano, Italia (según Bencivenga). Escala 1:10

\section{LA DIFUSIÓN DE ESTAS ÁNFORAS EN EL RESTO DE HISPANIA}

La constatación de la importación de ánforas itálicas en Hispania, gracias a los materiales localizados en Premià de Mar, nos ha inducido a buscar otros posibles casos similares a través del análisis de la bibiliografia especializada. Creemos que esta búsqueda ha dado un resultado positivo, localizando otros posibles 
ejemplares, de los que seguidamente efectuaremos un elenco en relación a los yacimientos arqueológicos en que fueron hallados.

\section{Sant Miquel del Cros}

\section{(Argentona, Maresme, Barcelona)}

En este lugar existió una villa romana, en la que se han hallado restos de estructuras arquitectónicas y tumbas de tégulas ${ }^{9}$; se han localizado en el mismo algunos fragmentos informes de sigillata africana $\mathrm{D}$ y un fragmento de borde de copa de sigillata gris estampillada gálica de la forma Rigoir 2 (Ribas 1975, figura 47: Prevosti 1981, n. ${ }^{\circ}$ 2).

Entre los hallazgos efectuados en este yacimiento figura un fragmento de cuello, borde, asas y parte del cuerpo de un ánfora que presenta estrechos paralelismos formales con los hallados en el Palmar Hotel, tanto por su borde pequeño $\mathrm{y}$ redondeado como por el perfil alargado y cilíndrico del cuello. Desgraciadamente, los materiales hallados en el yacimiento de Sant Miquel del Cros se encuentran actualmente en paradero desconocido, $y$ este fragmento anfórico se conoce tan sólo por un dibujo de Marià Ribas publicado por Prevosti (1981, figura $\left.63, n{ }^{\circ} 7\right)$ por lo que no es posible estudiar directamente esta pieza. Además de estos paralelismos tipológicos, el hallazgo (al parecer casi exclusivo) de otros materiales de época tardorromana permite apoyar la cronologia tardoantigua que atribuimos a este fragmento anfórico.

\section{Barcelona}

En las excavaciones efectuadas en el solar actualmente ocupado por la casa Padellàs de la ciudad de Barcelona durante los años treinta del presente siglo apareció un ánfora romana completa, que se conserva en el Museo de Historia de la Ciudad. Esta ánfora, como la mayoría de las cerámicas romanas halladas en Barcelona, puede considerarse sustancialmen-

- Sobre este asentamiento, véase Ribas 1975, págs. 100. 101 y Prevosti 1981, págs. 246 - 248 (con bibliografia anterior). Los datos referentes a la fase bajoimperial han sido recogidos en Járrega, en prensa. te inédita ${ }^{10}$, aunque Balil (1972, págs. 117-118) ha efectuado algunas consideraciones sobre ella, al tratar de relacionarla con las estructuras arquitectónicas halladas en el mismo lugar, que son objeto del estudio de dicho autor. La atipicidad de este ejemplar no fue pasada por alto por Balil, quien indica que «de no hallarse esta ánfora completa su perfil se atribuiria, como en otras ocasiones, a error del restaurador» (Balil 1972, págs. 117-118). Dicho autor considera asimismo que esta ánfora, a algunos "caracteres julio-claudios, une otros antoninianos", considerando que debe fecharse en los inicios del siglo II d. C. (Balil 1972, pág. 118).

$\mathrm{El}$ ánfora se conserva completa, y el perfil fusiforme y alargado, más bien masivo, de la misma, asi como la pequeñez y el perfil redondeado del labio la hacen muy similar al ejemplar completo del Palmar Hotel. La arcilla es de un color rosado intenso, aunque no podemos efectuar más precisiones puesto que no hemos estudiado directamente la pieza, que durante mucho tiempo ha estado expuesta en el emplazamiento aproximado de su hallazgo en el Museo de Historia de la Ciudad de Barcelona.

Tampoco en este caso contamos con un contexto arqueológico que nos permita una datación directa de la pieza, aunque existen algunos indicios dignos de consideración. Esta ánfora fue uno de los primeros hallazgos efectuados en el solar que hoy ocupa la Casa Padellàs de Barcelona, y sirvió de oportuna motivación para continuar los trabajos de excavación. Como permiten observar las estructuras arquitectónicas conservadas, en dicho lugar se ha documentado un importante desnivel del terreno entre las estructuras romanas más antiguas y las más superficiales (que aparentemente son de época tardo-antigua) "1 por esta razón, podemos pensar que esta ánfora, que se debió hallar en los estratos más modernos, corresponde al contexto de las estructuras más tardías, y por ello debe

\footnotetext{
${ }^{10}$ A pesar de ello, ha sido publicada una aceptable fotografia de la pieza en Duran i Sanpere 1943, pág. 55, figura 1 , aunque no tiene escala gráfica.

"Sobre la problemática de estas estructuras arquitectónicas, confrontar Balil 1972, págs. 115-124 y Járrega en prensa.
} 
tener una cronologia amplia pero en todo caso dentro del periodo tardo-antiguo (mejor que la datación en el siglo II que le atribuye Balil), lo que corrobora la cronología aproximada que puede atribuirse a la pieza desde el punto de vista tipológico.

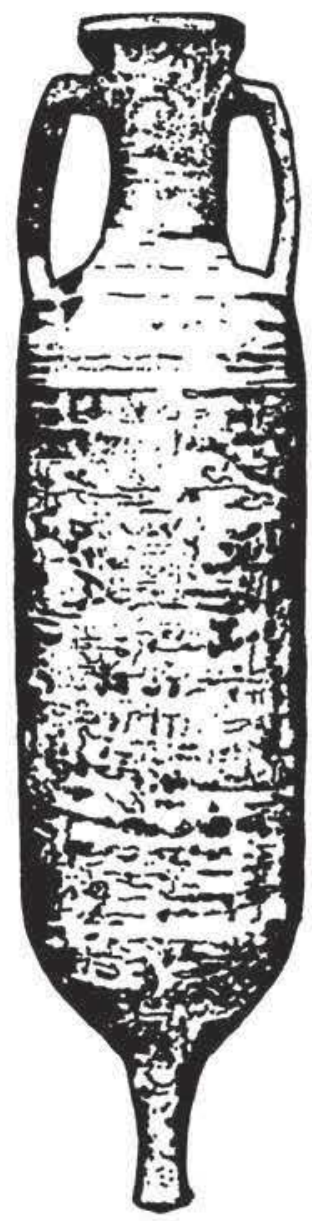

Figura 5.-Ánfora procedente de antiguas excavaciones de Barcelona (dibujo elaborado a partir de una fotografia publicada en Duran i Sanpere 1943, sin escala).

\section{El Saler (Valencia)}

Entre los hallazgos anfóricos submarinos efectuados en la playa de El Saler, cerca de Valencia, en el año 1981 figura un fragmento de cuello, borde y un asa (Fernández Izquierdo 1984 , pág. 73 , figura 28, n. $^{\circ} 218$ y pág. 80 ). Este ejemplar, recogido por Fernández Izquierdo
(1984, pág. 80) entre los fragmentos de forma indeterminada, creemos que corresponde a la producción que estamos estudiando, tanto por sus características tipológicas como por su composición física. El perfil cilindrico y alargado del cuello y el pequeño tamaño del borde, asi como la sección ovalada de las asas y el perfil poco anguloso de las mismas, son muy similares a los de los ejemplares documentados en el Palmar Hotel. El diámetro exterior del borde es de $14,5 \mathrm{cms}$.

Según Fernández Izquierdo (1984, pág. 80) la pasta es de color «naranja, porosa con escaso desgrasante de arenas negras»; esta descripción corresponde a una pasta identificable con la del ejemplar completo hallado en el Palmar Hotel. Dado que se trata de un elemento aislado y sin contexto no existen datos cronológicos externos, pero creemos, teniendo en cuenta los paralelismos expresados, que corresponde a la forma anfórica que estamos estudiando.

\section{Setúbal (Portugal)}

En el núcleo urbano de la ciudad de Setúbal se han recuperado en diferentes épocas varias ánforas romanas, casi siempre con un registro arqueológico deficiente, dado que se trata de hallazgos fortuitos ${ }^{12}$; entre este lote de materiales anfóricos existen dos ejemplares (de los cuales se ha publicado la reproducción gráfica de uno) que han sido publicados como pertenecientes a la forma Dressel 2/4 (Coelho-Soares y Tavares da Silva 1978, págs. 175-176 y figura $1, \mathrm{n}^{\circ} 1$ ).

El citado ejemplar del cual se ha publicado un dibujo (Coelho-Soares y Tavares da Silva 1978, figura $\left.1, n .^{\circ} 1\right)$ corresponde a un fragmento que conserva el cuello, el borde y las dos asas. El perfil cilíndrico y alargado del cueIlo, la pequeñez y la sección redondeada del borde y el perfil poco anguloso de las asas lo hacen muy similar a los ejemplares localizados en Gricignano y en el Palmar Hotel; la sección de las asas es bífida.

\footnotetext{
12 Véase Coelho-Soares y Tavares da Silva 1978, págs.
} $171-172$ 
Según la descripción de las arcillas publicada por Coelho-Soares y Tavares da Silva (1978, pág. 176) éstas son compactas y duras, con superficies alisadas-ásperas que presentan finas estrias y largos surcos acanalados horizontales. La composición del ejemplar dibujado muestra, según el análisis del microscopio, una fractura regular atravesada por pequeñas brechas, numerosas inclusiones calcáreas, algunas translúcidas y de tonalidad oscura, $\mathrm{y}$ raras inclusiones negras y vitreas. El otro ejemplar presenta una pasta diferente, con numerosas inclusiones de color negro, tipicas de los productos itálicos. Ahora bien, de este otro ejemplar (que se describe como más fragmentario) no se ha publicado ningún dibujo, por lo que no puede excluirse que se trate de una Dressel $2 / 4$ típica, tambièn de producción itálica pero de cronologia alto-imperial.

\section{Riudarenes (Constanti, Tarragonès, Tarragona)}

Citamos este hallazgo en último lugar, debido a que es el más inseguro (por su tipologia y posible cronología) de los que componen este elenco.

En el lugar llamado Riudarenes, a $900 \mathrm{~m}$. del núcleo urbano de Constanti ${ }^{13}$, las lluvias torrenciales pusieron al descubierto dos ánforas completas, que quedaron en propiedad particular, aunque se ha publicado sendos dibujos de las mismas (Papiol 1973-74, pág. 255, figura 9). A juzgar por dichos dibujos, una de estas ánforas (Papiol 1973-74, pág. 255, figura 9, izquierda; reproducida en Keay 1984, vol. I, pág. 81 , figura $21, \mathrm{n} .^{\circ} 6$ ) corresponde a la forma Keay XVI A-Almagro 50, producida en el Sur de Hispania, y que se fecha entre el siglo III y la primera mitad del v (Keay 1984, págs. 151 y 155 ).

La otra ánfora (Papiol 1973-74, pág. 255, figura 9, derecha) corresponde a grandes rasgos a la forma Dressel 2/4, aunque su perfil ligeramente más alargado y fusiforme de lo normal permite pensar que pueda atribuirse a la producción que estamos estudiando. De to-

${ }^{13}$ Sobre este yacimiento, véase Papiol 1973-74, pág. 255 y Gorges 1979, pág. 414. dos modos, resulta más cercano al de la Dressel 2/4 típica (incluyendo la sección del asa, que es totalmente bifida) que los otros ejemplares que estudiamos, por lo que debido a que no hemos podido analizar directamente la pieza (que únicamente conocemos por el dibujo que se ha publicado de la misma), presentamos esta posible asociación como una simple sugerencia poco segura. De todos modos, llama la atención que esta ánfora se hallase completa junto con otra también entera de la forma Keay $\mathrm{XVI}$, que si es con seguridad bajoimperial, aunque ello no nos permite asegurar que ambas perteneciesen al mismo contexto estratigráfico, lo cual por otro lado parece probable.

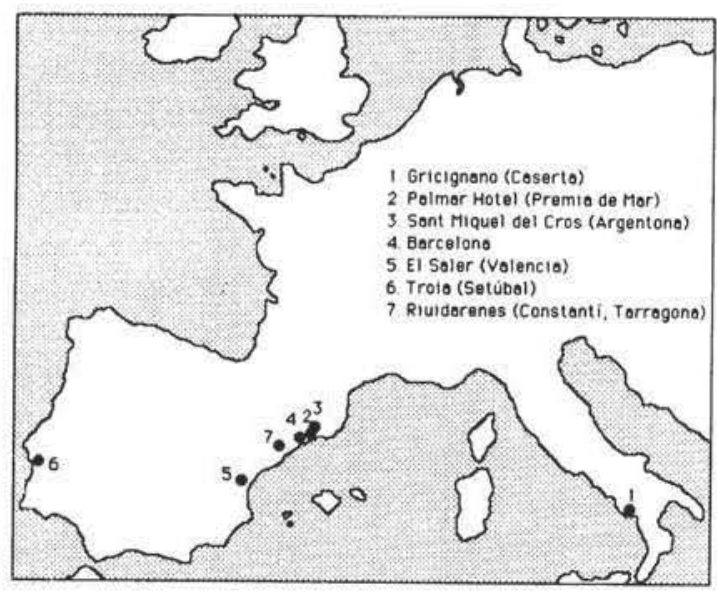

Figura 6.-Mapa de distribución de los hallazgos de ejemplares anfóricos similares a los del Palmar Hotel de Premià de Mar en el Mediterráneo occidental (diseño: Jordi Corbella, MMETP).

\section{CRONOLOGÍA}

Son escasos todavía los datos cronológicos que conocemos para datar estas ánforas. Los ejemplares del Palmar Hotel no pueden ser anteriores al siglo III, debido a que fueron reutilizados en una necrópolis, costumbre que se inicia, al parecer, en dicho siglo. El hecho de que correspondan solamente a dos tumbas en un amplio conjunto funerario formado por más de sesenta enterramientos de tégulas y en fosa, podría hacer pensar, como ya se ha dicho, en una datación antigua para ambas tumbas de 
ánforas, es decir, el siglo III d. C. Sin embargo, el hallazgo de una moneda de Constantino I entre las tierras de la necrópolis, pese a carecer del correspondiente registro estratigráfico, nos hace considerar la posibilidad de una cronologia posterior, ya en el siglo iv d. C., si bien tampoco cabe descartar una perduración del uso de esta necrópolis más o menos amplia.

El fragmento anfórico de El Saler (Valencia), que de todos los que citamos (además de los del Palmar Hotel) creemos que es el que con mayor seguridad puede atribuirse a la producción que estudiamos aqui, no ofrece ningún contexto arqueológico que permita datarlo, como tampoco las ánforas de Setúbal (Portugal) y el posible ejemplar de Riudarenes (Tarragona). La datación más aproximada la proporcionan las excavaciones italianas de Gricignano, que debido al hallazgo de un fragmento de sigillata gris estampillada reutilizado para cubrir la boca de una ánfora de la necrópolis (aunque perteneciente a otra forma anfórica distinta) no parecen poder datarse antes del último cuarto del siglo Iv.

Teniendo en cuenta todo lo expuesto, creemos que la cronologia de las ánforas objeto del presente estudio podria iniciarse quizás (aunque sin seguridad) en el siglo III, estando constatada sin duda en la segunda mitad del siglo Iv $y$ sin descartar una perduración hasta un momento indeterminado del siglo $\mathrm{V}$ como minimo. Los datos de las excavaciones de Gricignano, conjugados con las referencias de las fuentes escritas (véase más adelante) parecen apuntar con mayor seguridad a una datación en la segunda mitad del siglo iv d. C.

\section{CONSIDERACIONES SOBRE EL TEMA}

Los hallazgos anfóricos del yacimiento campano de Gricignano y los que hemos estudiado, permiten documentar la existencia de un nuevo tipo anfórico de época bajoimperial y de producción itálica, que como podemos ver tuvo alguna difusión exterior, al menos en lo que se refiere a Hispania.

Dado que estamos en la fase inicial del conocimiento sobre estas producciones, son es- casos aún los resultados concretos que su estudio nos aporta, empezando por el tema mismo de la producción de estas ánforas. Efectivamente, tanto las ánforas de Gricignano como las del Palmar Hotel son sin duda (como demuestra el análisis visual de su composición física) productos itálicos, pero la zona concreta de su fabricación aún se desconoce. Lógicamente hemos de suponer que fueron (al menos en parte) producidas en Campania, donde se localiza el enclave de Gricignano; sin embargo, las diferencias en la composición de los dos ejemplares (por otro lado, sin duda itálicos) del Palmar Hotel puede hacer pensar en la existencia de diversos centros de producción, que de todos modos pudieron muy bien estar todos ellos situados en Campania.

Aunque evidentemente no contamos con datos arqueológicos directos que lo confirmen, podemos pensar que el producto que se envasó en estas ánforas fue el vino; el paralelismo formal con las ánforas tardo-republicanas y altoimperiales de la forma Dressel 2/4 (que siempre se ha considerado tipicamente vinaria) y el hecho de que se trate de producciones itálicas (teniendo en cuenta los datos proporcionados por las fuentes) asi permiten suponerlo.

Se conoce una ley de Graciano, fechada el 17 de septiembre del año 377 (C. Ib. XXI 2, 3) que hace referencia al vino itálico que se llevaba a Roma (...vino, quod ex urbicaria regione confectur...). Ello permite demostrar que en la segunda mitad del siglo IV d. C., la annona organizaba el aprovisionamiento de la ciudad de Roma con vino producido en otras regiones itálicas, principalmente la Campania ${ }^{14}$. Creemos que este vino debió ser, al menos parcialmente, el que se envasó en las ánforas documentadas en Gricignano. Como indica la identificación de éstas con los ejemplares hallados en Hispania, este vino campano no debió limitarse solamente a aprovisionar la Urbs, sino que debió crear suficientes excedentes capaces de exportarse (aunque fuese esporádicamente) a

14 Véase Mazzarino 1974, págs. 308-312; sobre la producción agrícola de Campania durante el Bajo Imperio, confrontar de Robertis 1948, pág. 95; Ruggini 1961, págs. 49, 107: Cracco Ruggini 1969, passim. 
otras provincias. al menos (como demuestran los hallazgos que hemos analizado) a Hispania.

Es tan reciente la identificación de la forma anfórica que estamos estudiando que todavia no se le ha atribuido una catalogación tipológica concreta, sino que ha habido que referirse a ella (tanto en el estudio de Bencivenga como en el nuestro) siempre de acuerdo con su similitud a la forma Dressel 2/4. Es dificil atribuir una clasificación concreta para estas ánforas, que quizás podriamos designar como «tipo Gricignano" debido al yacimiento en el que fueron documentadas por primera vez.

Un detalle curioso que nos permite conocer el ejemplar completo del Palmar Hotel es el hecho de que no se prescindió de comercializar ejemplares defectuosos como el citado, que está claramente deformado. Es posible que esto guarde relación con el carácter esporádico de la comercialización de estas ánforas, aunque todo ello está todavia por ver.

Por último, debemos señalar que la escasez con que se han documentado estas ánforas puede no ser tan grande, e incluso ser solamente aparente. Dada su estrecha similitud tipológica con la forma Dressel $2 / 4$, sin duda el hallazgo de ejemplares fragmentarios dificultará grandemente su identificación y facilitará su confusión con la citada forma, máxime cuando no se cuente con contextos arqueológicos claros, e incluso en tales casos, en los que podría erróneamente considerarse como material residual. Creemos que una revisión en profundidad de los fondos de museos y de los materiales de excavación podría depararnos algunas sorpresas.

\section{CONCLUSIONES}

Como conclusiones preliminares de este estudio, podemos establecer los puntos siguientes:

- Existió una producción vinaria en Italia (principalmente, $o$ acaso exclusivamente, en Campania) en la segunda mitad del siglo ıv d. C. (y posiblemente también antes), que se destinaba al aprovisionamiento de la ciudad de Roma.

- En el mismo período se produjeron en el área itálica unas ánforas que posiblemente guardan una lejana relación con las ánforas al- toimperiales de la forma Dressel $2 / 4$, por lo que podemos suponer que eran vinarias. Probablemente, en estas ánforas se envasó el vino que nos documentan las fuentes escritas.

- Estas ánforas (y por lo tanto, el vino itálico) además de aprovisionar la ciudad de Roma, debieron exportarse esporádicamente al exterior (como mínimo a Hispania) como demuestran los hallazgos españoles y portugueses. Incluso se transportaban ocasionalmente productos defectuosos, pero útiles para el cometido para el que fueron fabricados (como el ánfora del Palmar Hotel).

\section{BIBLIOGRAFIA}

AA.VV., 1981: Atlante delle forme ceramiche I. Ceramica fine romana nel bacino mediterraneo (medio e tardo Impero), Enciclopedia dell Arte Antica Classica e Orientale, Roma.

ArCE, J. 1982: El último siglo de la España romana: 284-409, Madrid.

ARCE, J. 1987: La «crisis» y el Bajo Imperio. Evolución politica. Organización administrativa. Sociedad y economia, Historia General de España y América, vol. II, 279-363, Madrid.

Arthur, P., 1985: Naples: Notes on the economy of a dark age city, Papers in Italian Archaeology, IV, BAR International series, 246, págs. 247-259, Oxford.

Arthur, P., 1986: Amphorae and the Byzantine World, Recherches sur les amphores grecques (Bulletin de Correspondance Héllenique, Supll. XIII), págs. 655-660, Paris.

Arthur, P., 1987: Precisazioni su di una forma anforica medio- imperiale dalla Campania, El vi a l'Antiguitat. Economia, producció $i$ comerç al Mediterrani occidental, págs. 401406, Badalona.

Arthur, P., 1989: Some observations on the economy of Bruttium under the Later Roman Empire, Journal of Roman Archaeology, 2, págs. 133-142, Ann Arbor.

BAL.IL, A., 1959: Arquitectura doméstica de la Barcelona romana, Oretania, págs. 126-129, Linares. 
Bst.It. A., 1972: Casa y urbanismo en la Espaǹa antigua (III). Casa familiar y vivienda colectiva en la España romana, Boletin del Seminario de Estudios de Arte y Arqueologia, 38, págs. 55-131, Valladolid.

Beltrán, M., 1970: Las ánforas romanas en España. Zaragoza.

Bt: TRAN, M., 1983: El aceite en Hispania a través de las ánforas: la concurrencia del aceite bético y africano, Producción y comercio del aceite en la Antigüedad, págs. 515-549, Madrid.

Bencivenga, C., 1987: Sulla diffusione delle anfore trado- imperiali in Campania: il complesso di Gricignano (Caserta), El vi a $l$ 'Antiguitat. Economia, producció $i$ comerç al Mediterrani occidental, págs. 395-400, Badalona.

Bonifay, M., 1986: Observations sur les amphores tardives à Marseille d'après les fouilles de La Bourse (1980-1984), Révue d'Archéologie Narbonnaise, 19, págs. 269-305. Narbona.

Bonifay, M.; Conges, G., y Leguilloux, M., 1989: Amphores tardives (Ve-VIle siècle) à Arles et à Marseille, Amphores romaines et historie économique: dix ans de recherche, págs. 660-663, Roma.

Cамвı, F., 1989: L'anfora di Empoli, Amphores romaines et histoire économique: dix ans de recherche, págs. 564-567, Roma.

Carandini, A., 1970: Produzione agricola e produzione ceramica nell'Africa di età imperiale, Studi Miscellanei, 15, págs. 95-281, Roma.

Carignani, A., 1986: La distribuzione delle anfore africane tra III e VII secolo, Società romana e impero tardoantico (A. Giardina, ed.), vol. III, págs. 273-277, Bari.

Coelho Soares, A., y Tavares da Silva, C., 1978: Anforas romanas da área urbana de Setúbal, Setúbal Arqueológica, IV, págs. 171$191,+9$ figuras, Setúbal.

CoLL, R., 1984: Un anell signatori a Santa Anna, Agrupació d'Estudis Cientifics i Culturals, 17, septiembre, 1984, págs. 1-3, Premià de Mar.

Coll, R., y CAzorla, F. 1987: El jaciment del Palmar Hotel. Campanya de salvament de l'any 1984, El Museu, 1, págs. 7-9, Premià de Mar.

Constncio: Correspondència amh Sant Agusti (ed. J. Amengual, 1987), Barcelona.

Cracco Rugigini, L., 1969: Le relazioni fiscali. annonarie e commerciali delle città campane con Roma nel IV sec. d. C., Studi Romani, XVII, págs. 133-146, Roma.

Duran I SANPl-RF, A., 1943: Vestigios de la Barcelona romana en la plaza del Rey, Ampurias, V, págs. 53-77, Barcelona.

Emplereur, J. Y., y Picon, M., 1986 A: A la recherche des fours damphores, Recherches sur les amphores grecques, págs. 103-126. París.

Empereur, J. Y., y Picon, M., 1989: Les regions de production d'amphores impériales en Mediterranée orientale, Amphores romaines et histoire economique: dix ans de recherche, págs. 223-248, Roma.

FERnÁndez Izquierdo, A. 1984: Las ánforas romanas de Valentia y de su entorno maritimo, Valencia.

FULFORD, M. G., 1980: Carthage: overseas trade and the political economy, c. AD 400700, Reading Medieval Studies, 6, págs. 68-70.

FUl.Ford, M. G., 1983: Pottery and the economy of Carthage and its hinterland, Opus, 2, fasc. 1, págs. 5-14, Roma.

Fulford, M. G., y PEACoCK, D. P. S., 1984: Excavations at Carthage: The British Mission. vol. 1.2. The Avenue du Président Habib Bourguiba. Salammbo, Sheffield.

Gall.ıo, P., 1990: A frique et Armorique. A propos d'une amphore d'Afrique du Nord mise au jour à Rennes, Antiquités Africaines, 26, págs. 223-229, París.

Garcia Moreno, L. A., 1972: Colonias de comerciantes orientales en la Peninsula Ibérica. Siglos v-vil, Habis, 3, págs. 127-154, Sevilla.

Gorges, J. G., 1979: Les villes hispano-romaines. Inventaire et problématique archéologique, Burdeos.

Hayes, J. W., 1972: Late Roman Pottery, Londres.

Hayes, J. W., 1980: Supplement to Late Roman Pottery, Londres. 
INCITTI, M., 1986: Osservazioni sulle anfore, en "Lungotevere Testaccio», Bolletino deIla Comissione Archeologica Comunale di Roma, XCl, págs. 586-593, Roma.

JARREGiA, R., 1987: Notas sobre la importación de cerámicas finas norteafricanas (sigillata clara D) en la costa oriental de Hispania durante el siglo vi e inicios del vil d. C., Actas del II Congreso de Arqueologia Medieval Española, vol. II, págs. 337-344, Madrid.

JARREGiA, R., 1990: Una àmfora tardo-romana a la Conca de Tremp: dades sobre el comerc d'importació a l'Antiguitat Tardana, La romanilzació del Pirineu. 8è Col.loqui Internacional d'Arqueologia de Puigcerdà, págs. 131-136, Puigcerdà.

JARrEciA, R., 1991: Cerámicas finas tardorromanas y del Mediterráneo oriental en España. Estado de la cuestión. Anejos de "Archivo Español de Arqueologia, XI, Madrid.

Jarrt:GA, R., en prensa: Poblamiento y economia en la costa Este de la Tarraconense en época tardorromana (siglos $(V-i t)$. Tesis Doctoral, Universidad Autónoma de Barcelona, 1992 (en prensa en microficha).

JARreGa, R., y Clariana, J. F., en prensa: Ceràmica xipriota i egípcia - B tardo-romana a la comarca del Maresme, III Reunión de Arqueología Cristiana Hispánica (Mahón, 1988).

KEAY, S. J., 1984: The Late Roman Amphorae in the Western Mediterranean. A tipology and economic study: the Catalan evidence, BAR International series, 196, 2 vols., Oxford.

KEAY, S. J., 1987: La importación de vino y aceite en la Tarraconense oriental en la Antigüedad, El vi a l'Antiguitat. Economia, producció $i$ comerç al Mediterrani occidental, págs. 383-395, Badalona.

Lamboglia, N., 1963: Nuove osservazioni sulla «terra sigillata chiara», Rivista di Studi Liguri, 24, págs. 145-212, Bordighera.

Llanas, J.; Montalbán, C., y Gómez, J. 1977: Restes romanes al «Palmar Hotel» de Premià de Mar, Quaderns de Prehistòria $i$ Arqueologia del Maresme, 1, págs. 19-20, Mataró.

ManACORDA, D., 1977: Le anfore, en AA.VV.
Ostia IV. Studi Miscellanei, 23, págs. $116-$ 266 y $359-383$, Roma.

MANACORI)A, D., 1987: Il vino dell'Etruria romana: l'anfora di Empoli, El vi a l'Antiguitat. Economia, producció $i$ comerç al Mediterrani occidental, págs. 43-48, Badalona.

Mayfrson, Ph., 1985: The Wine and Vineyards of Gaza in the Byzantine Period, Bulletin of the American School of Oriental Research, 257 , págs. $75-80$, Filadelfia.

Mazzarino, S., 1959: La fine del mondo antico, Milán.

Mazzarino, S., 1974: Il Basso Impero. Antico, tardoantico ed era costantiniana (2 vols.), Bari.

PAcetti, F., 1986: La distribuzione delle anfore orientali tra IV e VII secolo D. C., Società romana e impero tardoantico (A. Giardina, ed.), vol. III, págs. 278-284, Bari.

PAlol, P. de, 1967: Arqueología cristiana de la España romana (siglos $w-1 /$ ), MadridValladolid.

Panella, C., 1983 A: Le anfore africane della prima, media e tarda età imperiale: tipologia e problemi, Actes du Colloque sur la Céramique Antique, CEDAC, Dossier 1, págs. 171-196, Túnez.

PANella, C., 1983 B: Le anfore di Cartagine: nuovi elementi per la ricostruzione dei fiuggi commerciali del Mediterraneo in età imperiale: tipologia e problemi, Opus, 2, fasc. 1, págs. 43-73, Roma.

PANElla, C., 1986 A: Le anfore tardoantiche: centri di produzione e mercati preferenziali, Società romana e imperio tardoantico (A. Giardina, ed.), vol. III, págs. 251-277, Bari.

Panella, C., 1986 B: Le merci: produzioni, itinerari e destini, Società romana e impero tardoantico (A. Giardina, ed.), vol. III, págs. 431-459, Bari.

PAPIOL, L. 1973-1974: Noticias sobre hallazgos romanos en el término de Constantí, Boletín Arqueológico, época IV, fascículos 121-128, págs. 250-256, Tarragona.

Pavolini, C., 1982: Le lucerne in terra sigillata africana de esportazione: proposta di una tipologia, Actes du Colloque sur la Ceramique Antique, CEDAC, Dossier 1, págs. 141156, Túnez. 
Pavolini, C., 1983: Considerazioni sulla difusione delle lucerne in terra sigillata prodotte in Tunisia, Opus, 2, fasc. 1, , págs. 43-51, Roma.

Pavolini, C., 1986: La circolazione delle lucerne in terra sigillata africana, en (Giardina ed.) Società romana e impero tardoantico, vol. III, págs. 241-250, Bari.

PEACOCK, D. P. S. 1977: Roman Amphorae: Typology, Fabrics and Origins, Méthodes classiques et méthodes formelles dans l 'étude des amphores, págs. 261-278, Roma.

Peacock, D. P. S., y Williams, D. F., 1986: Amphorae and the Roman Economy. An Introductory Guide, Nueva York.

Prevosti, M., 1981: Cronologia i pohlament a l'àrea rural d'lluro, Mataró.

RoBERTIS, F. M. de, 1948: La produzione agricola in Italia dalla crisi del III secolo all 'età dei Carolingi. Bari.

RODÁ, I., 1990: Sarcofagi della botega di Cartagine a Tarraco, Atti del VII convegno di studio su "L'Africa romana», págs. 727-736, Sassari.

RouGé, J., 1966: Recherches sur l'organisation du commerce maritime en Mediterranée sous l'Empire Romain, Paris.

RUGGiNI, L., 1961: Economia e società nell 'Italia Annonaria. Rapporti fra agricoltura e commercio dal IV al VI sec. d. C, Milán.

TOMBER, R., y Williams, D., 1986: Late Roman Amphorae in Britain, Journal of Roman Pottery Studies, I, págs. 42-54.

TORTORELla, S., 1980: La sigillata africana a Cartagine fra il 400 d. C. e la conquista vandala: i dati dello scavo della missione archeologica italiana, Actes du Colloque sur la céramique antique, Carthage, CEDAC, dossier 1, págs. 125-139, Túnez.
Tortortlla, S., 1981: Ceramica di produzione africana e rinvenimenti archeologici sottomarini: analisis dei dati e dei contributi reciproci, Mélanges de l'Ecole Française de Rome, 93, vol. I, págs. 355380 , Roma.

TORTORFLLA, S., 1983: Produzione e circolazione della ceramica africana di Cartagine (V-VII), Opus, 2, págs. 15-30, Roma.

TORTORELLA, S., 1986: La ceramica fine da mensa africana dal IV al VII secolo d. C., Società romana e Impero Tardoantico (A. Giardina, ed.) vol. III, págs. 211-225 y 819-820, Bari.

TorTORELlA, S., 1987: La ceramica africana: un riesame della problematica, Céramiques Hellenistiques et Romaines, II, págs. 315 a 322; fig. 1 a 18, Paris.

ViLf:LLA, J., 1983-1984: Recerques sobre el comerç baix- imperial del nord-est de la Peninsula Ibèrica, Pyrenae, 19-20, págs. 191214, Barcelona.

VILFLLA, J., 1987: Relaciones exteriores de la Peninsula Ibérica durante la Baja Antigüedad. Prosopografia. Tesis doctoral microfichada, Universidad de Barcelona.

WhitTAKer, C. R., 1983: Late Roman Trade and Traders, en (Garnsey, P.; Hopkins, K., y Whittaker, C.) Trade in the ancient economy, págs. 163-180, Londres.

Williams, D. F., 1982: The petrology of certain Byzantine amphorae: some suggestions as to origins, Colloque sur la Céramique Antique, CEDAC, Dossier 1, págs. 99110, Túnez.

Zevi, F., y Tchernia, A., 1969: Amphores de Byzacene au Bas-Empire, Antiquités Africaines, 3, págs. 173-214. 